\title{
Selective and Potent in Vitro Antitrypanosomal Activities of Ten Microbial Metabolites
}

\author{
Kazuhiko Otoguro, Aki Ishiyama, Miyuki Namatame, Aki Nishihara, \\ Toshiaki Furusawa, Rokuro Masuma, Kazuro Shiomi, Yoko Takahashi, \\ Haruki Yamada, Satoshi Ōmura
}

Received: March 8, 2008 / Accepted: May 30, 2008

(C) Japan Antibiotics Research Association

\begin{abstract}
More than 400 compounds isolated from soil microorganisms, and catalogued in the antibiotic library of the Kitasato Institute for Life Sciences, were screened against African trypanosomes. Ten compounds were found to have selective and potent antitrypanosomal activity in vitro: aureothin, cellocidin, destomycin $\mathrm{A}$, echinomycin, hedamycin, irumamycin, LL-Z 1272 $\beta$, Omethylnanaomycin A, venturicidin A and virustomycin A. Results of the in vitro assays using the GUTat 3.1 strain of Trypanosomal brucei brucei and the STIB900 strain of T. $b$. rhodesiense are presented. Cytotoxicity was determined using a human MRC-5 cell line. This is the first report of antitrypanosomal activities of the 10 microbial metabolites listed above.
\end{abstract}

Keywords screening, in vitro, antitrypanosomal antibiotics, Trypanosomal brucei brucei, T. b. rhodesiense, HAT

\section{Introduction}

African trypanosomes, protozoan parasites of the genus Trypanosoma, transmitted through the bite of bloodfeeding tsetse flies (Glossina spp.), cause disease in cattle and in people. Human African trypanosomiasis (HAT), also known as sleeping sickness, is caused by infection with Trypanosoma brucei rhodesiense or T. b. gambiense and is a major threat to communities throughout sub-Saharan Africa. A third subspecies, T. b. brucei is responsible for the cattle disease, N'gana, but does not infect humans. Accurate statistics for HAT are difficult to estimate the World Health Organization (WHO) estimated that, in 2000, some 300,000 individuals were affected by the disease, a figure far in excess of the 27,000 cases reportedly diagnosed and treated that year. With increased surveillance activities in the last 7 years, recent estimates indicate that there are 70,000 cases, causing 25,000 deaths annually [1, $2]$.

Currently, only four drugs are registered for the treatment of HAT: pentamidine, suramin, melarsoprol and eflornithine (Fig. 1). Pentamidine and suramin are used in the first or early stage of $T$. b.gambiense and $T$. $b$. rhodesiense infections. Melarsoprol is used in the advanced stage of both forms of the disease, while eflornithine is only used in the advanced stage of $T$. $b$. gambiense infections and is not effective against $T$. $b$. rhodesiense. Today, increasing numbers of patients, $20 \sim 25 \%$ in certain foci, are no longer responding to melarsoprol treatment, probably due to evolving drug resistance. Although expensive, eflornithine is an effective alternative drug for the treatment of $T$. $b$. gambiense patients who do not respond to melarsoprol [3].

All four drugs used to treat HAT are unsatisfactory, since they cannot be given orally and all are hampered by severe toxicity and increasing resistance of the parasites.
K. Otoguro (Corresponding author), A. Ishiyama, M. Namatame, A. Nishihara, T. Furusawa: Research Center for Tropical Diseases, The Kitasato Institute, 5-9-1 Shirokane, Minato-ku, Tokyo 108-8642, Japan, E-mail: otoguro@lisci.kitasato-u.ac.jp
S. Ōmura, H. Yamada, Y. Takahashi, K. Shiomi, R. Masuma: Kitasato Institute for Life Sciences and Graduate School of Infectious Control Sciences, Kitasato University, 5-9-1 Shirokane, Minato-ku, Tokyo 108-8641, Japan 


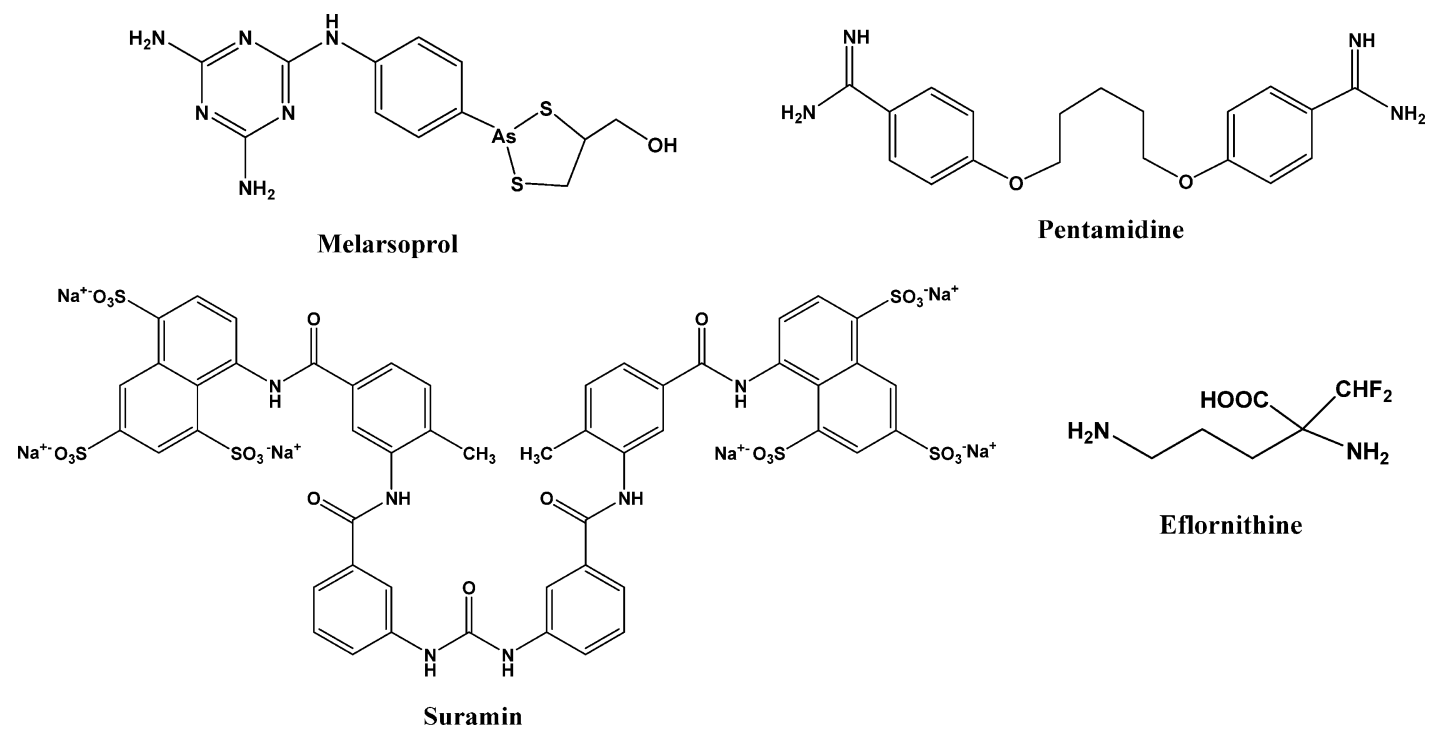

Fig. 1 Structures of the currently used antitrypanosomal drugs.

Melarsoprol for example, the only drug for $2^{\text {nd }}$-stage infections caused by T. b. rhodesiense, causes around 5.0\% fatalities due to severe adverse effects [4]. Consequently, there is an urgent need for new antitrypanosomal drugs which have novel structures and mechanisms of action and which are both safe and effective.

In the course of our screening program to discover new antitrypanosomal antibiotics, by screening metabolites from soil microorganisms, we have discovered 10 compounds that display potent antitrypanosomal activity in vitro. We report the results of sensitivity tests on the GUTat 3.1 strain of T. b. brucei and the STIB900 strain of $T$. $b$. rhodesiense using the four commonly used antitrypanosomal drugs as well as detailing the novel antitrypanosomal activity and cytotoxicity of the ten antibiotics in vitro.

\section{Materials and Methods}

\section{Parasites and History}

Trypanosoma brucei brucei strain GUTat 3.1 (Glasgow University, Trypanozoon antigenic type 3.1) was donated Dr. Y. Yabu (Nagoya City University, Japan). It is a cloned derivative of a stock EVE (Edinburgh Veterinary Expedition) 10 that was originally isolated in 1996 from a naturally infected bovine in Uganda. The original clone was provided by Dr. P. R. Gardiner, International Livestock Research Institute (ILRI), Nairobi, Kenya. A HAT parasite, T. b. rhodesiense strain STIB900, was supplied by Prof. R. Brun (Swiss Tropical Institute, Switzerland). It is a clone of a parasite, isolated in 1982 from a patient in Tanzania, which is known to be susceptible to all currently used drugs.

\section{Chemicals}

Test compounds were obtained from the antibiotic library of the Kitasato Institute for Life Sciences. Melarsoprol, suramin and eflornithine (DFMO) were provided by Prof. R. Brun (Swiss Tropical Institute, Switzerland). Pentamidine isothionate salt was obtained from SigmaAldrich Inc. (St. Louis, MO, USA). Iscove's Modified Dulbecco's Medium (IMDM, with L-glutamine and HEPES, without $\mathrm{NaHCO}_{3}$ ), Minimum Essential Medium (MEM) with Earle's salts, MEM non-essential amino acids solution and Penicillin-Streptomycin solution were obtained from Gibco Laboratories Life Technologies (Grand Island, NY, USA). Fetal Bovine Serum (FBS) was obtained from Sigma-Aldrich Inc. (St. Louis, MO, USA) and Horse Serum (HS) was obtained from Gibco Laboratores Life Technologies (Grand Island, NY, USA). Alamar Blue reagent was obtained from SigmaAldrich Inc. (St. Louis, MO, USA). Other chemicals were commercially available and of analytical grade.

\section{In Vitro Antitrypanosomal Assay against T. brucei Species}

T. b. brucei GUTat 3.1 strain was cultured in IMDM with $3.024 \mathrm{~g} /$ liter $\mathrm{NaHCO}_{3}, 100 \mu \mathrm{M}$ hypoxanthine, $30 \mu \mathrm{M}$ thymidine, $40 \mu \mathrm{M}$ adenosine, $1.0 \mathrm{mM}$ sodium pyruvate, $50 \mu \mathrm{M}$ L-glutamine, $100 \mu \mathrm{M} \quad 2$-mercaptoethanol and $50 \mathrm{Unit} / \mathrm{ml}$ of penicillin and $50 \mu \mathrm{g} / \mathrm{ml}$ of streptomycin 
containing $10 \%$ heat-inactivated $\mathrm{FBS}$ at $37^{\circ} \mathrm{C}$, under $5.0 \%$ $\mathrm{CO}_{2}-95 \%$ air, according to the method of Yabu et al. [5]. T. $b$. rhodesiense STIB900 strain was cultured in MEM with Earle's salts supplemented with $25 \mathrm{mM}$ HEPES, $1.0 \mathrm{~g} /$ liter additional glucose, $2.2 \mathrm{~g} /$ liter $\mathrm{NaHCO}_{3}$, $10 \mathrm{ml} /$ liter MEM non-essential amino acids $(100 \times)$, $0.2 \mathrm{mM}$ 2-mercaptoethanol, $1.0 \mathrm{mM}$ sodium pyruvate, $0.1 \mathrm{mM}$ hypoxanthine $50 \mathrm{Unit} / \mathrm{ml}$ of penicillin and $50 \mu \mathrm{g} / \mathrm{ml}$ of streptomycin containing $15 \%$ heat-inactivated $\mathrm{HS}$ at $37^{\circ} \mathrm{C}$, under $5.0 \% \mathrm{CO}_{2}-95 \%$ air, according to the method of Baltz et al. [6]. In vitro antitrypanosomal activity of test compounds was determined by a dose response curve using Alamar Blue according to the method of Räz et al. and Tasdemir et al. [7, 8] with some modification. Ninety five $\mu 1$ of the trypanosomes suspension $\left(2.0 \sim 2.5 \times 10^{4}\right.$ trypanosomes $/ \mathrm{ml}$ for GUTat 3.1 strain or $2.0 \sim 3.0 \times 10^{4}$ trypanosomes $/ \mathrm{ml}$ for STIB 900 strain) of bloodstream forms was seeded in a 96-well microplate, and $5.0 \mu \mathrm{l}$ of a test compound solution (dissolved in 5.0\% dimethylsulfoxide) was added. After the incubation for 72 hours at $37^{\circ} \mathrm{C}$ under $5.0 \% \mathrm{CO}_{2}-95 \%$ air, $10 \mu \mathrm{l}$ of the fluorescent dye Alamar Blue was added to each well. After a further incubation for $3 \sim 6$ hours at $37^{\circ} \mathrm{C}$ under $5.0 \%$ $\mathrm{CO}_{2}-95 \%$ air, the plate was read at $528 / 20 \mathrm{~nm}$ excitation wavelength and $590 / 35 \mathrm{~nm}$ emission wavelength by a FLx800 fluorescent plate reader (Bio-Tek Instrument, Inc. Vermont, USA). Data were transferred into a graphic program (Excel) and the $\mathrm{IC}_{50}$ values were determined by using the fluorescent plate reader software (KC-4, BioTek).

Stock cultures were kept in 24-well tissue culture plates at $37^{\circ} \mathrm{C}$ under $5.0 \% \mathrm{CO}_{2}-95 \%$ air.

\section{Cytotoxicity Tests on MRC-5 Cells}

Cytotoxicity was assayed against a human diploid embryonic cell line MRC-5 as described previously [9].

\section{Results}

\section{Antitrypanosomal Activity and Cytotoxicity of Currently Used Drugs}

The drug sensitivity of the GUTat 3.1 strain is not known. Conversely, the STIB900 strain is known to be susceptible to all existing antitrypanosomal drugs [10]. We therefore first established the in vitro drug sensitivity of the GUTat 3.1 and the STIB900 strains against the four common trypanocidal drugs. Suramin, pentamidine, melarsoprol and eflornithine were tested against the two T. brucei strains and MRC- 5 cells and $\mathrm{IC}_{50}$ values were determined (Table 1). Melarsoprol showed the highest antitrypanosomal activity against both parasite strains. The GUTat 3.1 strain was 85 -fold more sensitive to the drug than STIB900. The sensitivity to pentamidine was the same for both strains. For suramin, STIB900 was 30 -fold more sensitive than GUTat 3.1 while for eflornithine the sensitivity was only double. The cytotoxicity of the existing drug was also determined using MRC-5 cells. Melarsoprol and pentamidine showed $\mathrm{IC}_{50}$ values in the low $\mu \mathrm{g} / \mathrm{ml}$ range whereas for suramin and eflornithine, the $\mathrm{IC}_{50}$ values were $>100 \mu \mathrm{g} / \mathrm{ml}$.

To compare the antitrypanosomal activities and cytotoxicities, we calculated the selectivity index ( $\mathrm{SI}:\left[\mathrm{IC}_{50}\right.$ for MRC-5 cells $] /\left[\mathrm{IC}_{50}\right.$ for trypanosome strain]) (Table 1). The SIs were in a range $>44$ to 127,273 for GUTat 3.1 and in a range $>96$ to 3,807 for STIB900. Melarsoprol and pentamidine present SI values $>1,000$, peaking at $>100,000$ for melarsoprol and the GUTat 3.1 strain. For eflornithine it is difficult to determine a reasonable SI value because very high drug concentrations are tolerated by mammalian cells.

Table 1 In vitro antitrypanosomal activity and cytotoxicity of drugs used to treat human African trypanosomiasis

\begin{tabular}{|c|c|c|c|c|c|}
\hline \multirow{3}{*}{ Compound } & \multicolumn{3}{|c|}{$\mathrm{IC}_{50}(\mathrm{ng} / \mathrm{ml})$} & & \\
\hline & \multicolumn{2}{|c|}{ Antitrypanosomal activity } & \multirow{2}{*}{$\begin{array}{l}\text { Cytotoxicity } \\
\text { MRC-5 }\end{array}$} & \multicolumn{2}{|c|}{ Selectivity index (SI) } \\
\hline & GUTat 3.1 & STIB900 & & MRC/GUTat & MRC/STIB \\
\hline Melarsoprol & 0.011 & 0.94 & 1,400 & 127,273 & 1,489 \\
\hline Pentamidine & 1.6 & 1.5 & 5,710 & 3,569 & 3,807 \\
\hline Suramin & 1,580 & 52.0 & $>100,000$ & $>63$ & $>1,923$ \\
\hline Eflornithine & 2,270 & 1,040 & $>100,000$ & $>44$ & $>96$ \\
\hline
\end{tabular}


Table 2 In vitro antitrypanosomal activity and cytotoxicity of 10 microbial metabolites

\begin{tabular}{|c|c|c|c|c|c|}
\hline \multirow{3}{*}{ Compound } & \multicolumn{3}{|c|}{$\mathrm{IC}_{50}(\mathrm{ng} / \mathrm{ml})$} & & \\
\hline & \multicolumn{2}{|c|}{ Antitrypanosomal activity } & \multirow{2}{*}{$\begin{array}{c}\text { Cytotoxicity } \\
\text { MRC-5 }\end{array}$} & \multicolumn{2}{|c|}{ Selectivity index (SI) } \\
\hline & GUTat 3.1 & STIB900 & & M/GUTat & M/STIB \\
\hline Aureothin & 1.4 & 1.1 & $>25,000$ & $>17,857$ & $>22,727$ \\
\hline Cellocidin & 150 & 30 & 5,910 & 39 & 179 \\
\hline Destomycin A & 330 & 210 & 21,140 & 64 & 101 \\
\hline Echinomycin & 20 & 14 & 6,310 & 316 & 451 \\
\hline Hedamycin & 14 & 18 & $>25,000$ & $>1,786$ & $>1,389$ \\
\hline Irumamycin & 20 & 31 & $>12,500$ & $>625$ & $>403$ \\
\hline LL-Z $1272 \beta$ & 49 & 59 & 13,620 & 278 & 231 \\
\hline O-methylnanaomycin A & 210 & 16 & 4,890 & 23 & 306 \\
\hline Venturicidin A & 120 & 540 & $>25,000$ & $>208$ & $>185$ \\
\hline Virustomycin A & 0.45 & 480 & 80 & 178 & 0.2 \\
\hline
\end{tabular}

\section{In Vitro Antitrypanosomal Activity and Cytotoxicity of 10 Antibiotics}

The in vitro antitrypanosomal activity of the 10 microbial metabolites was determined using GUTat 3.1 (T. b. brucei) and $\operatorname{STIB900~(T.~b.~rhodesiense).~The~} \mathrm{IC}_{50}$ values are presented in Table 2. Virustomycin A and aureothin showed the highest antitrypanosomal activity, with $\mathrm{IC}_{50}$ values around $1.0 \mathrm{ng} / \mathrm{ml}$ which is comparable to pentamidine (Tables 1 and 2). Echinomycin, hedamycin, irumamycin and LL-Z $1272 \beta$ were 10 -fold less active than virustomycin $A$ and aureothin, with $\mathrm{IC}_{50}$ values of $14 \sim 59 \mathrm{ng} / \mathrm{ml}$ for both trypanosome strains. Cellocidin, destomycin A, $O$ methylnanaomycin A and venturicidin A were the least active compounds against GUTat 3.1 but their $\mathrm{IC}_{50}$ values can still be considered as active. Interestingly, cellocidin and $O$-methylnanaomycin A resulted in much lower $\mathrm{IC}_{50}$ values for STIB900 as compared to the GUTat 3.1 strain.

The cytotoxicity of the 10 compounds were evaluated against a human diploid embryonic cell line (MRC-5). The $\mathrm{IC}_{50}$ values are listed in Table 2. Virustomycin A was the only compound with a pronounced cytotoxicity, having an $\mathrm{IC}_{50}$ value of $80 \mathrm{ng} / \mathrm{ml}$. Cellocidin, echinomycin and $O$ methylnanaomycin A were revealed to be slightly cytotoxic, demonstrating $\mathrm{IC}_{50}$ values of $5 \sim 6 \mu \mathrm{g} / \mathrm{ml}$, while the remaining six compounds had $\mathrm{IC}_{50}$ values of $>12.5 \mu \mathrm{g} / \mathrm{ml}$ and do not seem to be cytotoxic.

Among the tested compounds, aureothin showed the highest SI with values of $>17,857$ for GUTat 3.1 and $>22,727$ for STIB900. It exhibited a significantly better SI value for $T$. $b$. rhodesiense than any other compound. Echinomycin, hedamycin, irumamycin, LL-Z 1272 $\beta$, venturicidin A and virustomycin A showed SIs $>100$ for GUTat 3.1. The SI values for cellocidin and destomycin A were in a lower range of $40 \sim 180$, based on the lower antitrypanosomal activity of these compounds.

\section{Discussion}

Aureothin is a $\gamma$-pyrone antibiotic, and is reported to have antitumor, antifungal and pesticide activity [11 13], and we previously reported that it showed potent nematocidal activity against the pine wood nematode [14]. The mode of action of aureothin has been reported as a non-specific inhibition of NADH: ubiquinone oxidoreductase (complex I) on bovine heart, fungal and bacterial cells [15].

Cellocidin is an amide antibiotic, and is reported to have antitumor and antibacterial activity $[16,17]$. The mode of action of cellocidin is via inhibition of the $\alpha$-ketoglutaratesuccinate system in the Krebs' cycle in Xanthomonas oryzae [18] and inhibition of nucleic acid synthesis in tumor cells [19].

Destomycin A is an aminoglycoside antibiotic and is reported to have antibacterial and anthelmintic activity [20 22]. The mode of action of destomycin A is the inhibition of polypeptide synthesis in cells of Escherichia coli and stimulation of adenylate cyclase in several animal tissues [23, 24].

Echinomycin is a cyclic depsipeptide antibiotic containing two quinoxaline moieties and is reported to have antibacterial and antitumor activity $[25,26]$. The mode of action of echinomycin is reported to be intercalation with 


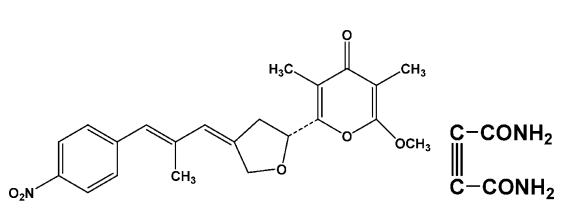

Aureothin

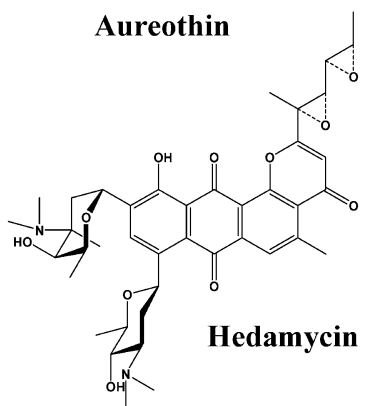

Cellocidin<smiles>CC(C)=CCCC(C)CCCC(C)CCc1c(O)c(C)c(C)c(O)c1O</smiles>

LL-Z 1272ß

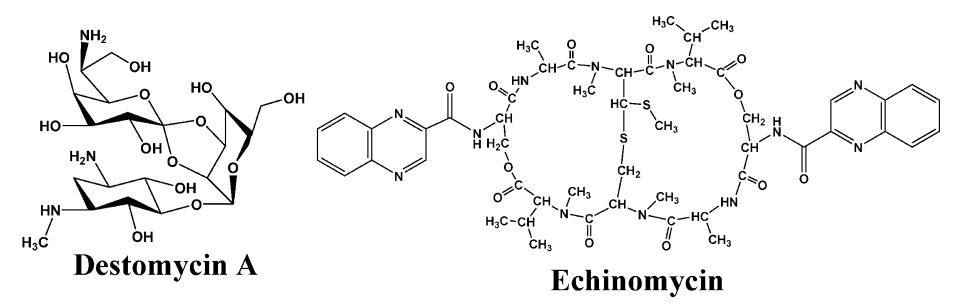

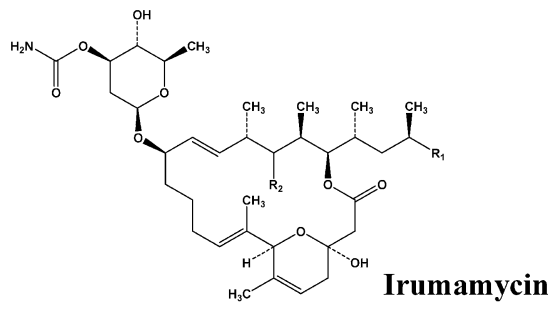

Venturicidin $A \underbrace{\mathrm{O}_{\mathrm{O}}}_{\mathrm{OH}} \overbrace{\mathrm{CH}_{3}}$<smiles>CCCC1CC2=C(C(=O)c3c(O)cccc3C2=O)C(C)O1</smiles>

$O$-Methylnanaomycin A

Fig. 2 Structures of antitrypanosomal antibiotics.

DNA $[25,26]$.

Hedamycin is an anthraquinone antibiotic exhibiting antitumor, antibacterial and anti-Tetrahymena pyriformis (anti-protozoal) activity [27]. Recently, we reported that it also possesses selective and potent antimalarial activity [28]. The mode of action of anthraquinone antibiotics is inhibition of nucleic acid synthesis [27].

LL-Z $1272 \beta$ is a terpenoid antibiotic and is reported to have anti-T. pyriformis (anti-protozoal) and antitumor activity $[29,30]$, and we reported that it showed inhibition of testosterone $5 \alpha$-reductase from rat prostate [31]. A related antibiotic, ascofuranone, is reported to have in vitro and in vivo anti-trypanosomal activities [32,33]. The mode of action of ascofuranone is inhibition of the mitochondrial electron-transport system in trypanosomes [32].

$O$-Methylnanaomycin A is a semi-synthetic analogue of nanaomycin A, a naphtoquinone antibiotic, and $O-$ methylnanaomycin $\mathrm{A}$ is reported to exhibit antifungal activity [34]. The mode of action of nanaomycin A is via inhibition of the respiratory chain-linked flavin dehydrogenase in bacterial cells [35].

Irumamycin and venturicidin A are similar to the 20membered ring macrolide antibiotics and both antibiotics are reported to have antifungal activity [36, 37]. For venturicidin A, antimalarial activity has also identified [38]. The mode of action of venturicidin $\mathrm{A}$ is inhibition of phosphoryl transfer reactions (in rat liver mitochondria) and inhibition of mitochondrial adenosine triphosphatase of T. pyriformis $[39,40]$.

Virustomycin A is an 18-membered ring macrolide antibiotic, reportedly having antiviral and anti-Trichomonas foetus (anti-protozoal) activities [41, 42]. The mode of action of virustomycin A is through interference with the formation of the phosphate donor(s) in the ATP-forming system (in T. foetus) [42].

Recently, Berriman et al., proposed several molecular targets in T. brucei determined from the available sequence of the T. brucei genome. One of them is mitochondorial electron transport and oxidative phosphorylation, including ATP synthase [43]. Some of the antitrypanosomal antibiotics we describe in this article (aureothin, cellocidin, the ascofuranone related LL-Z 1272 $\beta, O$ methylnanaomycin $\mathrm{A}$, irumamycin, venturicidin $\mathrm{A}$ and virusomycin A) may actually inhibit $T$. brucei by inhibition of mitochondrial functions.

The mode of action of aminoglycoside antibiotics, such as destomycin A, is via inhibition of polypeptide synthesis, that of cyclic depsipeptide antibiotics (such as 
echinomycin) via intercalation with DNA, and anthraquinone antibiotics (such as hedamycin) through inhibition of nucleic acid synthesis are all well documented [23, 25 27]. Destomycin A, echinomycin and hedamycin may also inhibit $T$. brucei in the same manner and detailed studies of the mode of action need to be undertaken to provide further evidence.

Further studies, including in vivo tests in animal models of trypanosomal infection and characterization of other biological activities of aureothin, cellocidin, destomycin A, echinomycin, hedamycin, irumamycin, LL-Z 1272 $\beta$, Omethylnanaomycin $\mathrm{A}$, venturicidin $\mathrm{A}$ and virustomycin $\mathrm{A}$ are in progress.

Acknowledgements This work was supported, in part, by funds from the Drugs for Neglected Diseases initiative (DNDi), and a grant for All Kitasato Project Study (AKPS). We are grateful to Dr. Y. Yabu, Nagoya City University and Prof. R. Brun and M. Kaiser, Swiss Tropical Institute, and Prof. S. Croft, Dr. E. Chatelain, Dr. J.-R. Ioset, Dr. C. Brünger and Miss F. Hirabayashi, DNDi, for valuable discussions. We also thank Miss H. Sekiguchi (The Kitasato Institute) for her technical assistance throughout this work.

\section{References}

1. http://www.dndi.org/

2. WHO. Human African trypanosomiasis (sleeping sickness): epidemiological update. Weekly Epidemiol Rec 81: 71-80 (2006)

3. Milord F, Pépin J, Loko L, Ethier L, Mpia B. Efficacy and toxicity of eflornithine for treatment of Trypanosoma brucei gambiense sleeping sickness. Lancet 340: 652-655 (1992)

4. Fairlamb AH. Chemotherapy of human African trypanosomiasis: current and future prospects. Trends Parasitol 19: 488-494 (2003)

5. Yabu T, Koide T, Ohta N, Nose M, Ogihara Y. Continuous growth of bloodstream forms of Trypanosoma brucei brucei in axenic culture system containing a low concentration of serum. Southeast Asian J Trop Med Public Health 29: 591-595 (1998)

6. Baltz T, Baltz D, Giroud Ch, Crockett J. Cultivation in a semi-defined medium of animal infective forms of Trypanosoma brucei, T. equiperdum, T. evansi, T. rhodesiense and T. gambiense. EMBO J 4: 1273-1277 (1985)

7. Räz B, Iten M, Grether-Buhler Y, Kaminsky R, Brun R. The Alamar Blue assay to determine drug sensitivity of African trypanosomes (T. b. rhodesiense and T. b. gambiense) in vitro. Acta Trop 68: 139-147 (1997)

8. Tasdemir D, Kaiser M, Brun R, Yardley V, Schmidt TJ, Tosun F, Rüedi P. Antitrypanosomal and antileishmanial activites of flavoids and their analogues: In vitro, in vivo, structure-activity relationship, and quantitative structureactivity relationship studies. Antimicrob Agents Chemother 50: 1352-1364 (2006)

9. Otoguro K, Kohana A, Manabe C, Ishiyama A, Ui H, Shiomi K, Yamada H, Ōmura S. Potent antimalarial activities of polyether antibiotic, X-206. J Antibiot 54: 658-663 (2001)

10. Bacchi CJ, Brun R, Croft SL, Alicea K, Bühler Y. In vivo trypanocidal activities of new S-adenosylmethionine decarboxylase inhibitors. Antimicrob Agents Chemother 40: 1448-1453 (1996)

11. Washizu F, Umezawa H, Sugiyama N. Chemical studies on a toxic product of Streptomyces thioluteus, auteothin. J Antibiot 7A: 60 (1954)

12. Schmitz H, Woodside R. Aureothin, a new antifungal antibiotic. Antibiot Chemother 5: 652-657 (1955)

13. Oishi H, Hosaka T, Okutomi T, Suzuki K, Ando K. Pesticidal activity of aureothin. Agric Biol Chem 33: 1790-1791 (1969)

14. Otoguro K, Liu Z-X, Fukuda K, Li Y. Iwai Y, Tanaka H, Ōmura S. Screening for new nematocidal substances of microbial origin by a new method using the pine wood nematode. J Antibiot 41: 573-575 (1988)

15. Friedrich $\mathrm{T}$, van Heek $\mathrm{P}$, Leif $\mathrm{H}$, Ohnishi $\mathrm{T}$, Forche E, Kunze B, Jansen R, Trowitzsch-Kienast W, Hofle G, Reichenbach $\mathrm{H}$, Weiss H. Two binding sites of inhibitor in NADH: ubiquinone oxidoreductase (complex I). Relationship of one site with the ubiquinone-binding site of bacterial glucose: ubiquinone oxidoreductase. Eur J Biochem 219: 691-698 (1994)

16. Suzuki S, Nakamura G, Okuma K, Tomiyama Y. Cellocidin, a new antibiotic. J Antibiot 11: 81-83 (1958)

17. Suzuki S, Okuma K. The structure of cellocidin. J Antibiot 11: 84-86 (1958)

18. Tomomasa M. Mode of action of agricultural antibiotics developed in Japan. Residue Reviews 25: 93-106 (1969)

19. Tanaka T, Sakaguchi K, Otake N, Yonehara H. Impoved screening method for inhibitors of nucleic acid synthesis. Agric Biol Chem 32: 100-103 (1968)

20. Kondo S, Sezaki M, Koike M, Shimura M, Akita E, Satoh K, Hara T. Destomycins A and B, two new antibiotics produced by a Streptomyces. J Antibiot 18: 38-42 (1965)

21. Kondo S, Iinuma K, Naganawa H, Shimura M, Sekizawa Y. Structural studies on destomycins A and B. J Antibiot 28: 79-82 (1975)

22. Sawada I. Anthelmintic effect of destomycin A against poultry tapeworms. Jpn J Parasit 21: 45-48 (1972)

23. Kojima M, Nojiri C, Yamada Y. Studies on Mode of action of destomycin A. Meiji Seika Kenkyu Nenpo 10: 1-8 (1969)

24. Suzuki A, Ishida K. Activating effect of destomycin A on adenylate cyclase from several animal tissues. FEBS Lett 144: 326-328 (1982)

25. Katagiri K, Yoshida $\mathrm{T}$, Sato K. In Antibiotics III: Mechanism of action of antimicrobial and antitumor agents. 
Ed. Corcoran JW, Hahn FE, Springer, Berlin, pp. 234-51 (1974)

26. Waring MJ. In Antibiotics V/Part 2: Mechanism of action of antieukaryotic and antiviral compounds. Ed. Hahn FE, Springer, Berlin, pp. 173-194 (1979)

27. Bradner WT, Heinemann B, Gourevitch A. Hedamycin, a new antitumor antibiotic. II. Biological properties. Antimicrob Agents Chemother 1966: 613-618 (1967)

28. Ui H, Ishiyama A, Sekiguchi H, Namatame M, Nisihara A, Takahashi Y, Shiomi K, Otoguro K, Ōmura S. Selective and potent in vitro antimalarial activities found in four microbial metabolites. J Antibiot 60: 220-222 (2007)

29. Ellested GA, Evans RH, Jr, Kunstmann MP. Some new terpenoid metabolite from an unidentified Fusarium species. Tetrahedron 25: 1323-1334 (1969)

30. Hayakawa S, Minato H, Katagiri K. The ilicolins, antibiotics from Cylindrocladium ilicicola. J Antibiot 24: 653-654 (1971)

31. Takamatsu S, Rho M-C, Masuma R, Hayashi M, Komiyama $\mathrm{K}$, Tanaka H, Ōmura S. A novel testosterone $5 \alpha$-reductase inhibitor, 8',9'-dehydroascochlorin produced by Verticillium sp. FO-2787. Chem Pharm Bull 42: 953-956 (1994)

32. Minagawa N, Yabu Y, Kita K, Nagai K, Ohta N, Meguro K, Sakajo S, Yoshimoto A. An antibiotic, ascofuranone, specifically inhibits respiration and in vitro growth of long slender bloodstream forms of Trypanosoma brucei brucei. Mol Biochem Parasitol 81: 127-136 (1996)

33. Yabu Y, Minagawa N, Kita K, Nagai K, Honma M, Sakajo S, Koide T, Ohta N, Yoshimoto A. Oral and intraperitoneal treatment of Trypanosoma brucei brucei with a combination of ascofuranone and glycerol in mice. Parasitol Int 47: 131-137 (1998)

34. Tanaka H, Marumo H, Nagai T, Okada M, Taniguchi K, Ömura S. Nanaomycins, new antibiotics produced by a strain of Streptomyces. III. A new component, nanaomycin $\mathrm{C}$, and biological activities of nanaomycin derivatives. J
Antibiot 28: 925-930 (1975)

35. Hayashi M, Unemoto $\mathrm{T}$, Minami-Kakinuma S, Tanaka H, Ömura S. The mode of action of nanaomycins D and A on a gram-negative marine bacterium Vibrio Alginolyticus. J Antibiot 35: 1078-1085 (1982)

36. Ōmura S, Tanaka Y, Nakagawa A, Iwai Y, Inoue M, Tanaka $\mathrm{H}$. Irumamycin, a new antibiotic active against phytopathogenic fungi. J Antibiot 35: 256-257 (1982)

37. Brufani M, Keller-Schierlein W, Loeffler W, Mansperger I, Zaehner H. Metabolite products of microorganisms. LXIX. Venturicidin B, cotrycidin, and the sugar structural units of venturicidin A and B. Helv Chim Acta 51: 1293-1304 (1968)

38. Warhurst DC, Thomas SC. The chemotherapy of rodent malaria, XXXI. The effect of some metabolic inhibitors upon chloroquine-induced pigment clumping (CIPC) in Plasmodium berghei. Ann Trop Med Parasitol 72: 203-211 (1978)

39. Walter P, Lardy HA, Johnson D. Antibiotics as tools for metabolic studies. X. Inhibition of phosphoryl transfer reactions in mitochondria by peliomycin, ossamycin, and venturicidin. J Biol Chem 242: 5014-5018 (1967)

40. Unitt MD, Lloyd D. Effects of inhibitors on mitochondrial adenosine triphosphatase of $T$. pyriformis ST. J Gen Microbiol 126: 261-266 (1981)

41. Ōmura S, Shimizu H, Iwai Y, Hinotozawa K, Otoguro K, Hashimoto H, Nakagawa A. AM-2604 A, a new antiviral antibiotic produced by a strain of Streptomyces. J Antibiot 35: 256-257 (1982)

42. Ōmura S, Otoguro K, Tanaka H. The mode of action of a novel 18-memberd macrolide, virustomycin A (AM-2604 A), on Trichomonas foetus. J Antibiot 36: 1755-1761 (1983)

43. Berriman $\mathrm{M}$, et al. The Genome of the African Trypanosome Trypanosoma brucei. Science 309, 5733: 416-435 (2005) 